\title{
Studies on structure, growth and characterization of third order nonlinear optical 2-amino-5-chloropyridinium-4-amino benzoate single crystal
}

\author{
M. KRISHNAKUMAR ${ }^{1, *}$, K. ThIRUPUGALMANi ${ }^{2}$, S. BRAHADEESWARAN $^{2}$ \\ ${ }^{1}$ Department of Physics, University College of Engineering-Dindigul 624 622, India \\ ${ }^{2}$ Crystal Research Laboratory, Department of Physics, Bharathidasan Institute of Technology, Anna University, \\ Tiruchirappalli 620024, India
}

\begin{abstract}
Optically transparent single crystals of 2-amino-5-chloropyridinium-4-amino benzoate (2A5CP4AB) were grown at room temperature using solution growth technique. The structure was solved with a support of single crystal XRD, which revealed that the title compound belongs to the monoclinic crystal system having centrosymmetric space group P21/n. The UV-Vis spectrum and photoluminescence properties of the title compound showed the optical transmittance and emission behavior of the compound. The optical band gap was evaluated using the Tauc plot and it was found to be about $3.53 \mathrm{eV}$. The third order nonlinear optical behavior of the crystal was determined using Z-scan technique. Mechanical properties of the title compound were studied using Vickers microhardness study.
\end{abstract}

Keywords: solution growth; nonlinear optical properties; photoluminescence

\section{Introduction}

Organic single crystals having large nonlinear optical figure of merit for frequency conversion are essential for various scientific and technological applications. The design and development of a nonlinear optical single crystalline material with superior usefulness has been spotlighted in recent years. Single crystals having high values of nonlinear optical coefficients are employed in applications, such as frequency conversion, frequency mixing and optical data storage systems. Organic single crystalline materials possess better second and third order nonlinear optical properties when compared with inorganic materials. A variety of nonlinear optical materials and complexes are formed between aminopyridine and carboxylic acid derivatives. Their structural and nonlinear optical behaviors have been studied due to their influence on laser technology and optical data storage devices [1-3].

*E-mail: Krishnakumar05@gmail.com
The fundamental structure of an organic molecule relies on strong delocalization of $\pi$-bond arrangement in an organic material. Furthermore, the overlap of $\pi$-orbitals can generate charge carrier distribution in a molecule. Third order nonlinear optical effects require strong delocalization of $\pi$-electron conjugation system in organic molecules. The formation of an organic molecule with a proper electron donor and acceptor on either ends of $\pi$-electron conjugation system could be a key factor to produce better nonlinear optical responses [4-6]. For example, extensive research has been conducted on 4-N,N-dimethylamino-4'$\mathrm{N}^{\prime}$-methyl-stilbazolium tosylate (DAST) crystals. The DAST single crystals were grown in a form of bulk or thin films to be used in nonlinear optical and electrooptic devices for creation and detection of terahertz (THz) frequencies [7, 8]. Organic complexes, in which molecules having extremely improved electronic nonlinear optical polarization response possess conjugate systems, show several advantages over inorganic materials [6]. Though a material showing second order nonlinear optical efficiency is very much needed, the requirement 
of third order molecular crystals and complexes still persists. The extremely strong delocalization of $\pi$ electrons decides on molecular polarizability and third order molecular polarizability in an organic molecule [6].

One of the starting materials - 4-aminobenzoic acid (PABA) - is a constituent of vitamin B family used in the formation of esters, salts, folic acid, azo dyes and other organic compounds. It acts as a bacterial cofactor used in the synthesis of folic acid [9], and as an antagonist to the action of the drug sulfonilamide in competition for essential metabolites growth [10]. Since PABA donates and accepts hydrogen, it has proved to be one of the most adaptable reagents for structural expansion in direct hydrogen bonding relationships via carboxylic acid and amine functional groups [11]. Due to this extension property, PABA shapes and encourages hydrogen bonding linkages via carboxylic acid and amine functional groups [12]. This type of hydrogen bond linkages have been examined and studied in various centrosymmetric complexes, such as PBCA (piperidinium-p-bromo/p-chloro/pmethyl benzoic acid [13, 14], P21/c (pyridinyl-2methylene-4-aminobenzoic acid [11], C2/c(bis(4aminobenzoic acid-kN) dichloridozinc (II)) [15]. It is interesting to know the organization between 4amino benzoic acid and 2-amino-5-chloropyridine from crystal engineering perspective. In this article, 2-amino-5-chloropyridinium-4-aminobenzoate (2A5CP4AB) was successfully synthesized and single crystals were grown using solution growth technique. In this manuscript, our results on crystal growth and UV-Vis, photoluminescence and nonlinear optical studies, have been reported, to the best of our knowledge, for the first time.

\section{Experimental}

\subsection{Crystal growth}

The growth of $2 \mathrm{~A} 5 \mathrm{CP} 4 \mathrm{AB}\left(\mathrm{C}_{12} \mathrm{H}_{12} \mathrm{~N}_{3} \mathrm{ClO}_{2}\right)$ complex single crystals was carried out from the title compound. The salt of the title compound was obtained by adding equimolar amounts of methanol solutions of 2-amino 5-chloro pyridine and 4-amino benzoic acid (Fig. 1). The two solutions were firmly mixed together and stirred well for about 3 hours to obtain a white color precipitate, and the resultant solution was filtered through Whatmann 40 filter paper. The white color precipitate was separated from the solution by drying it at $45^{\circ} \mathrm{C}$.

The synthesized powder of $2 \mathrm{~A} 5 \mathrm{CP} 4 \mathrm{AB}$ was further purified by consecutive recrystallization process with the help of methanol solvent. During crystallization process, the beaker was covered with a regular filter paper and care was taken to reduce the temperature gradient and mechanical vibrations. The filtrate was kept in environment under room temperature for crystallization. The saturated solution of the title compound was prepared at different temperatures using methanol solvent.

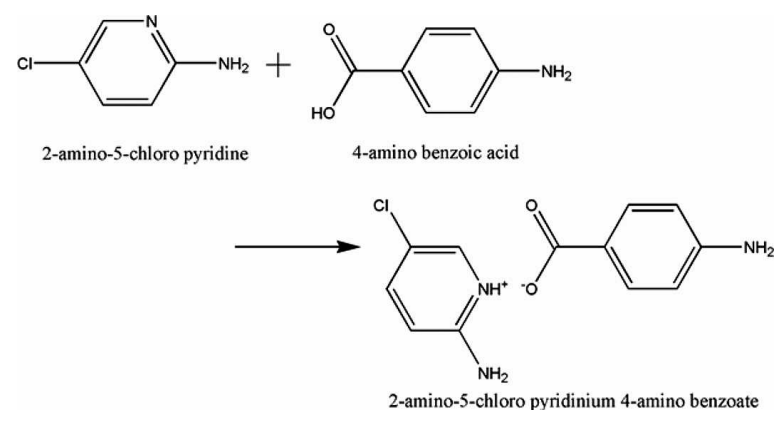

Fig. 1. Reaction scheme of 2A5CP4AB.

The solubility and metastable zone width were studied to examine the possibility of growing the title complex crystals by slow cooling and solution growth technique. Saturated solution of $2 \mathrm{~A} 5 \mathrm{CP} 4 \mathrm{AB}$ complex was prepared at room temperature using solubility curve. Moreover, the saturated solution was filtered and allowed to evaporate in temperature controlled growth chamber. Herein, optically transparent, inclusion free crystals grown by spontaneous nucleation were used as seed material to grow optically transparent bulk single crystals [16]. Theoretical Bravais, Friedel, Donnay and Harker (BFDH) morphology of the crystalline compound was determined with the help of a unit cell and positional coordinates. From BFDH morphology of the title compound the $\left(\begin{array}{lll}0 & 2 & 0\end{array}\right)$ and $(0-2 \quad 0)$ were the most predominant planes at the expense of other planes and it is also evident from Fig. $2 b$. 

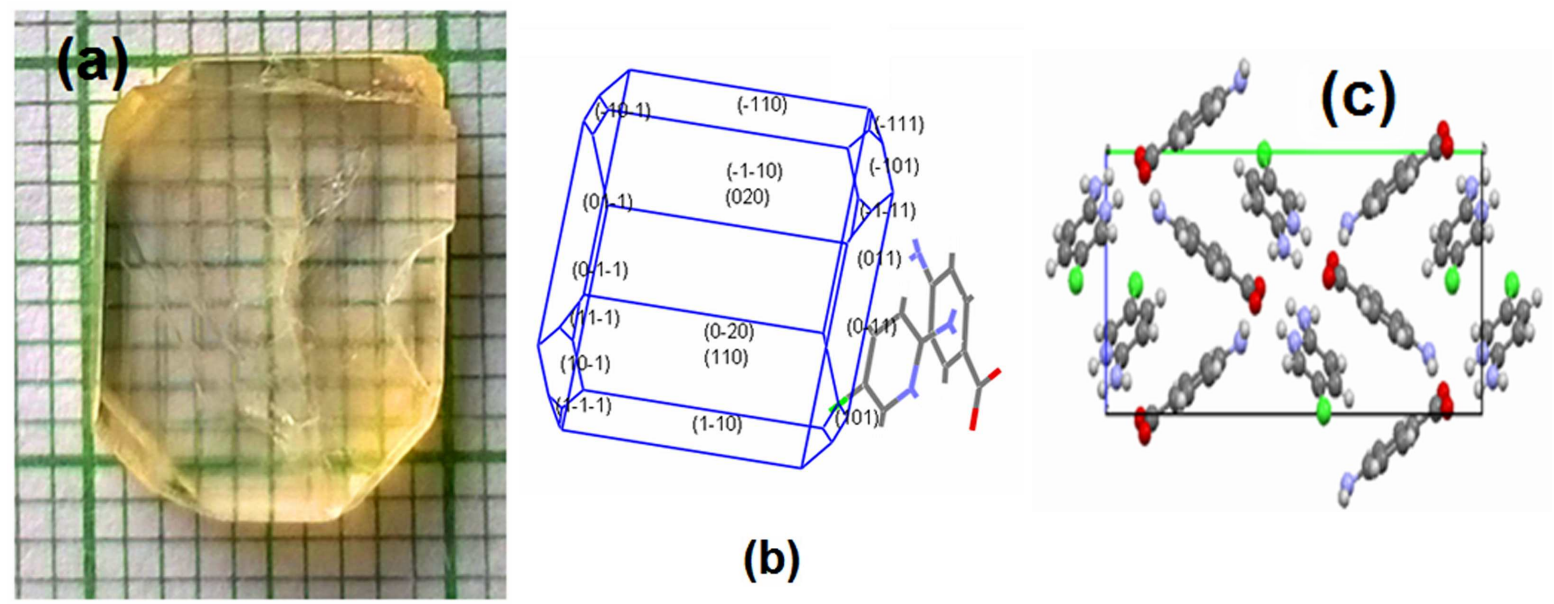

(b)

Fig. 2. (a) as grown $2 \mathrm{~A} 5 \mathrm{CP} 4 \mathrm{AB}$ crystal, (b) its $\mathrm{BFDH}$ morphology and (c) packing diagram.

\subsection{Characterization details}

The phase formation of $2 \mathrm{~A} 5 \mathrm{CP} 4 \mathrm{AB}$ complex was established using powder X-ray diffraction method. The powder X-ray diffraction study for the title compound was carried out with the help of PANalytical X'Pert PRO X-ray diffractometer employing $\mathrm{CuK} \alpha$ radiation. The intensity data were recorded between 10.022 and $79.8192 \theta$ range with the step scan of $0.01486^{\circ}$ in the time interval of 12.89 s. UV-Vis spectrum of $2 \mathrm{~A} 5 \mathrm{CP} 4 \mathrm{AB}$ crystal was recorded in the range from $200 \mathrm{~nm}$ to $1000 \mathrm{~nm}$ for a sample $2 \mathrm{~mm}$ thick, employing UV-Vis spectrophotometer (model Lambda 35). The accuracy of the measurement was $\pm 0.2 \mathrm{~nm}$. Photoluminescence of the title compound crystal was also measured with the aid of Varian Cary Eclipse Fluorescence Spectrophotometer. The sample was first excited at $280 \mathrm{~nm}$ with a xenon flash lamp and emission from the sample was fed to a monochromator arranged in the apparatus. Emission intensity received from the sample was recorded at various wavelengths.

Third order nonlinear optical properties of the title compound, i.e. nonlinear refractive index and nonlinear absorption coefficient were examined with the help of Z-scan technique. In the Z-scan technique, a continuous wave $\mathrm{He}-\mathrm{Ne}$ laser of $632.8 \mathrm{~nm}$ wavelength with power output of $15 \mathrm{~mW}$ was used as a main source of light. Initially, the measurement of nonlinear absorption coefficient $(\beta)$ was carried out by open aperture Z-scan method. In open aperture technique, the measurement of intensity related absorption of the sample was carried out by moving the sample in positive and in negative direction of Z-axis, without placing aperture in front of the detector apparatus. In closed aperture Z-scan method, the aperture was located in far field position and the energy transmitted through the sample was measured for evaluation of nonlinear refractive index $\left(\mathrm{n}_{2}\right)$. The Vicker's microhardness behavior of crystalline $2 \mathrm{~A} 5 \mathrm{CP} 4 \mathrm{AB}$ specimen was studied using Shimadzu microhardness tester.

\section{Results and discussion}

\subsection{Solubility and metastable zone width studies}

Solubility and metastable zone width are important parameters used to optimize, scale-up and develop crystallization process. Solubility measurement of any material in a given solvent reveals nucleation, required quantity of solute substance for the growth process and allows determining the cooling rate of the growth process. Supersaturation is a driving force for growing better quality crystals and it has an effect on the quality of the crystal. It is essential that the solubility of a substance was moderate to grow better quality single crystals. Solute must remain in the solution till 
elevated level of supersaturation is achieved to encourage spontaneous nucleation. In general, metastable zone width is determined from the difference between saturation temperature and nucleation temperature of a system [17]. Metastable zone width (MSZW) of a system is strongly influenced by several parameters, such as saturation temperature, solution concentration, mixture of the constituent elements in the solution, impurities present in the starting materials and the rate at which supersaturation is generated in the solution $[18,19]$. The solubility and metastable zone width of $2 \mathrm{~A} 5 \mathrm{CP} 4 \mathrm{AB}$ in methanol solvent in a temperature range of $20{ }^{\circ} \mathrm{C}$ to $40{ }^{\circ} \mathrm{C}$ are depicted in Fig. 3.

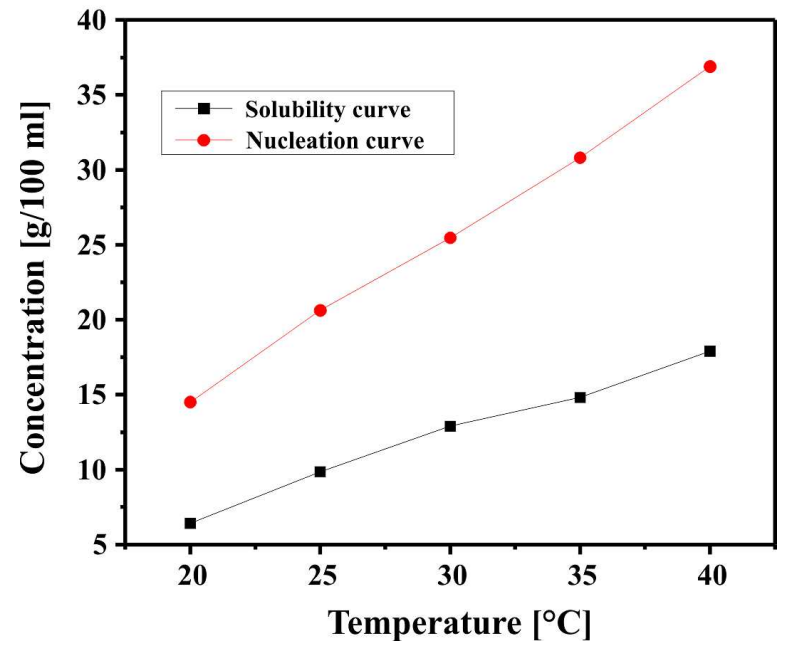

Fig. 3. Solubility and metastable zone width of $2 \mathrm{~A} 5 \mathrm{CP} 4 \mathrm{AB}$ in methanol solvent.

\subsection{X-ray diffraction and morphology studies}

The planes of diffraction in the powder X-ray diffraction data were indexed with the help of Mercury software [20]. The simulated X-ray diffraction pattern obtained from the Mercury software reveals a good agreement with the experimental data obtained from powder X-ray diffraction pattern. The lattice parameters obtained from the single crystal X-ray diffraction data are $\mathrm{a}=6.9879$ (4) $\AA$, $\mathrm{b}=22.0074$ (13) $\AA, \quad \mathrm{c}=8.0554 \quad$ (5) $\AA$, $\beta=92.796(1)^{\circ}$, volume $\mathrm{V}=1237.33$ (13) $\AA^{3}$ and the number of molecules per unit cell is four. The obtained results are consistent with the reported values [21]. The compound crystallizes in a centrosymmetric space group (P21/n - monoclinic), and it is the basic requirement for third harmonic generation (THG) material. Fig. 4 shows a comparison of powder X-ray diffraction data with Mercury software simulated X-ray diffraction pattern. The sharp peaks in the experimentally obtained powder X-ray diffraction pattern evidence crystalline nature of the title compound.

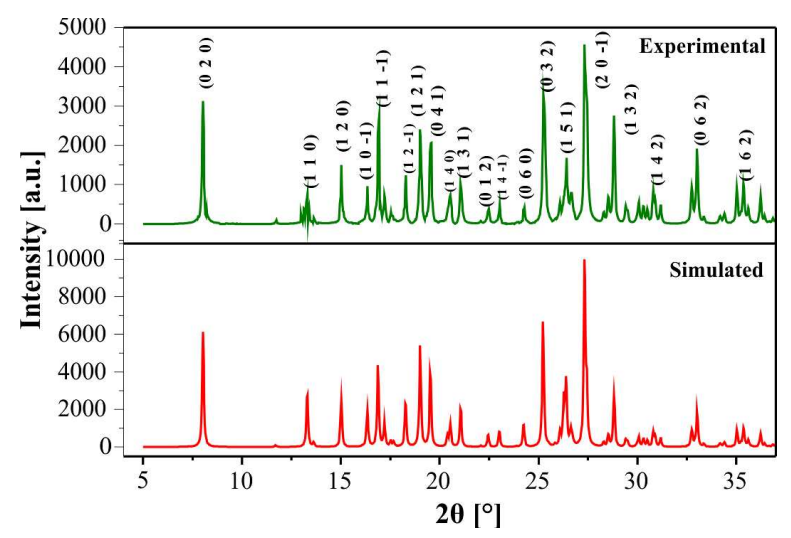

Fig. 4. Comparison of powder X-ray diffraction data with simulated X-ray diffraction pattern.

\subsection{UV-Vis, PL spectroscopy and refrac- tive index studies}

In order to study linear optical characteristics, the grown crystals of $2 \mathrm{~A} 5 \mathrm{CP} 4 \mathrm{AB}$ with a thickness of about $2 \mathrm{~mm}$ were subjected to UV-Vis-NIR spectral analysis in the wavelength range from $200 \mathrm{~nm}$ to $1100 \mathrm{~nm}$ (Fig. 5b). Fig. 5a shows UV-Vis absorption spectra of 2A5CP, PABA and 2A5CP4AB. In NLO crystalline compounds, an improved optical transmittance is one of the most important properties. Due to the presence of absorption peaks between shorter and longer wavelength regions in a material, conversion efficiency of the material is altered. Hence, it is essential to monitor absorption in this range. From the spectrum in Fig. 5b, it is evident that the UV cut-off wavelength of the grown $2 \mathrm{~A} 5 \mathrm{CP} 4 \mathrm{AB}$ crystal is $323 \mathrm{~nm}$. The crystal is entirely transparent beyond the cut-off wavelength up to $1200 \mathrm{~nm}$. The absorption peaks 
of PABA observed at $204 \mathrm{~nm}$ and $219 \mathrm{~nm}$ are due to $\pi-\pi^{*}$ transitions of aromatic ring. The peak at $204 \mathrm{~nm}$ in PABA due to the local excitation evolved from -COO- group.

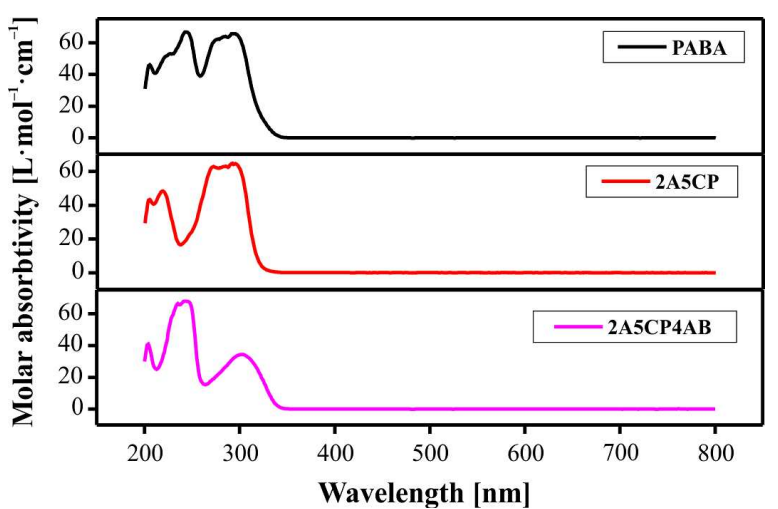

(a)

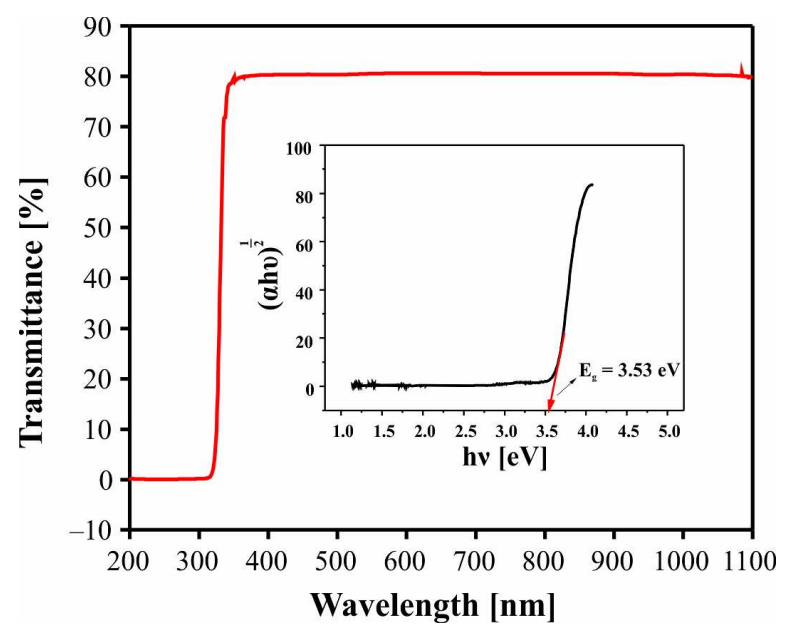

(b)

Fig. 5. (a) absorption spectra of $2 \mathrm{~A} 5 \mathrm{CP} 4 \mathrm{AB}, \mathrm{PABA}$ and 2A5CP, (b) optical transmission spectrum of 2A5CP4AB single crystal with the Tauc's plot (inset).

The band at $275 \mathrm{~nm}$ is due to the presence of amino group in ortho position of the ring. In 2A5CP absorption spectrum, the occurrence of secondary band at $303 \mathrm{~nm}$ is due to the strong electron donating groups, such as $\mathrm{Cl}$ and $\mathrm{NH}_{2}$, in fifth and second position of pyridine ring, respectively [22]. Due to transition between 'non-bonding' $\mathrm{n}$ orbital and 'anti-bonding' orbital represented as $\pi^{*}$, strong absorption peak is observed around $294 \mathrm{~nm}$ in $2 \mathrm{~A} 5 \mathrm{CP} 4 \mathrm{AB}$ absorption spectrum [23]. From the absorption spectrum of $2 \mathrm{~A} 5 \mathrm{CP}$ and $2 \mathrm{~A} 5 \mathrm{CP} 4 \mathrm{AB}$, the hypsochromic shift of absorption band (from $303 \mathrm{~nm}$ in $2 \mathrm{~A} 5 \mathrm{CP}$ to $294 \mathrm{~nm}$ in $2 \mathrm{~A} 5 \mathrm{CP} 4 \mathrm{AB}$ ) is observed due to the increased electron donating ability of $2 \mathrm{~A} 5 \mathrm{CP}$ to PABA, which consequently confirms the formation of the title compound. The transparent character of a crystal is a required property for second and third harmonic light with wavelengths $\lambda=532 \mathrm{~nm}$ and $\lambda=354.6 \mathrm{~nm}$, respectively, originating from Nd:YAG laser radiation with the wavelength $\lambda=1.064 \mathrm{~nm}$ [24]. Quantum manipulations were employed to determine optical absorption coefficient for the grown $2 \mathrm{~A} 5 \mathrm{CP} 4 \mathrm{AB}$ crystal. It is understood that quantum manipulations using quantum perturbation theory treats the incident radiation as quantum perturbation and couples valence band energy levels with the energy levels in conduction band. The optical absorption coefficient $(\alpha)$ of the grown 2A5CP4AB crystal was obtained from the following relation:

$$
\alpha=\frac{2.303 \log (1 / T)}{d}
$$

where $d$ is the thickness of the crystal and $T$ is the transmittance. The absorption coefficient $(\alpha)$ of $2 \mathrm{~A} 5 \mathrm{CP} 4 \mathrm{AB}$ was determined using the following relation:

$$
(\alpha h v)=A\left(h v-E_{g}\right)^{n}
$$

where A represents a constant. $\mathrm{h}$ represents Planck's constant, $v$ is frequency corresponding to incident photons and $\mathrm{n}$ represents an index that characterizes the optical absorption process and whose value is theoretically equal to $1 / 2,3 / 2,2$ and 3 depending on the transitions, such as direct allowed, direct forbidden, indirect allowed, indirect forbidden, respectively. The above equation is suitable for allowable direct transition between simple parabolic bands [25]. The optical energy gap $\left(E_{g}\right)$ of $2 \mathrm{~A} 5 \mathrm{CP} 4 \mathrm{AB}$ was calculated using Tauc's plot $(\alpha \mathrm{h} v)^{1 / \mathrm{n}}$ versus $\mathrm{h} v$, by extending the linear section of the curve near $(\alpha \mathrm{h} v)^{1 / \mathrm{n}}=0$ as shown in the inset on Fig. 5b. The band gap value of $2 \mathrm{~A} 5 \mathrm{CP} 4 \mathrm{AB}$ crystal was estimated at $3.53 \mathrm{eV}$. The large band gap value of this crystal shows the wide transmittance in visible and NIR (near infrared) region.

The refractive index measurement of the title compound was carried out with the help of $\mathrm{He}-\mathrm{Ne}$ 
laser source of $632 \mathrm{~nm}$ wave length. The refractive index of the sample was found by clamping the sample against the prism and by measuring the critical angle $\theta$ for the sample interface. A laser beam of $632 \mathrm{~nm}$ wavelength was directed toward the prism; the beam which stroke the prism face was totally reflected from the prism towards photodetector in the arrangement. The value of refractive index measured for the title compound was 1.461 at $\lambda=632 \mathrm{~nm}$.

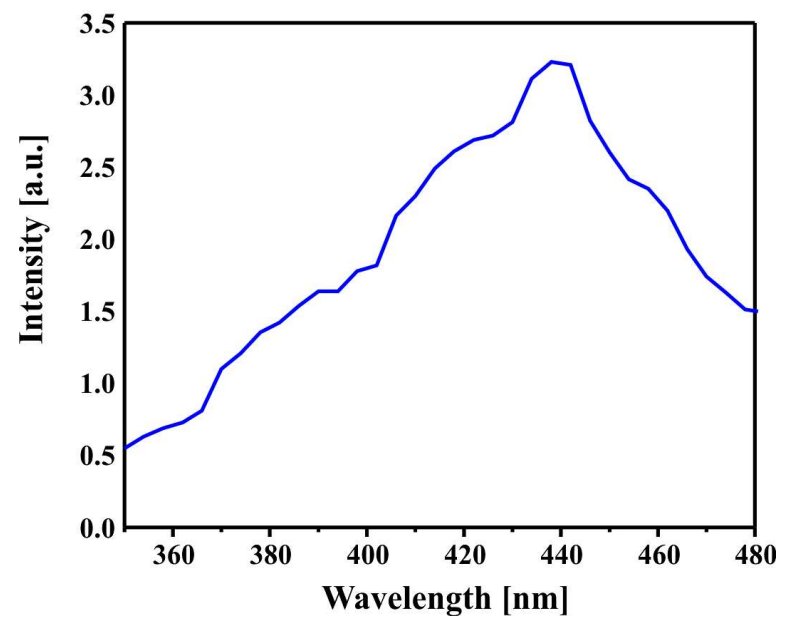

Fig. 6. PL spectrum of 2A5CP4AB crystal.

Photoluminescence (PL) spectrum of $2 \mathrm{~A} 5 \mathrm{CP} 4 \mathrm{AB}$ crystal recorded in the range of $300 \mathrm{~nm}$ to $550 \mathrm{~nm}$ is shown in Fig. 6. Herein, the crystal was excited at $300 \mathrm{~nm}$. The broad spectrum with a peak at $440 \mathrm{~nm}$ can be compared with the intensity of polymer composites and conducting polymers [30]. However, the intensity of the plot is gradually increasing while moving from the lower wavelength to higher wavelength region. It is observed that beyond $440 \mathrm{~nm}$, the intensity decreases slowly. The cause for improved PL emission of the title compound $2 \mathrm{~A} 5 \mathrm{CP} 4 \mathrm{AB}$ follows from the fact that the presence of $\mathrm{NH}$ (electron donating) group and $\mathrm{COOH}$ (electron pulling back) group improved $\pi$-electrons mobilization in the crystalline material. The occurrence of the intensive peak positioned at $440 \mathrm{~nm}$ is due to protonation of the amine group attached to the pyridinium ring moiety to the carboxyl group of the acid. The diminishing intensity at higher wavelength region of PL spectrum may be possibly due to the large barrier for rotation of $\mathrm{COOH}$ group around $\mathrm{C}-\mathrm{C}$ bond present in PABA [26].

\subsection{Z-scan studies}

The normalized transmittance of $2 \mathrm{~A} 5 \mathrm{CP} 4 \mathrm{AB}$ as a function of distance along the lens axis in far field, with open aperture and closed aperture is shown in Fig. 7. The peak and valley transmittance difference $\left(\Delta \mathrm{T}_{\mathrm{p}-\mathrm{v}}\right)$ [27] was evaluated from the value of phase shift $|\Delta \Phi|$, given by:

$$
\Delta T_{p-v}=0.406(1-S)^{0.25}|\Delta \Phi|
$$

Herein, $\Delta \Phi$ is the on-axis phase shift and $\mathrm{S}$ is the linear aperture transmittance. Linear aperture transmittance can be calculated using the following relation:

$$
S=1-\exp \left[\frac{-2 r_{a}^{2}}{\omega_{a}^{2}}\right]
$$

Herein, $r_{a}$ is the radius of aperture and $\omega_{a}$ is the spot diameter at focal length. The on axis phase shift $(\Delta \Phi)$ is related to the third order nonlinear refractive index $\left(\mathrm{n}_{2}\right)$ :

$$
n_{2}=\frac{\Delta \Phi}{k I_{0} L_{e f f}} \mathrm{~cm}^{2} / \mathrm{W}
$$

Herein, $\mathrm{k}=2 \pi / \lambda$, where, $\lambda$ is the wavelength of fundamental laser source, $\mathrm{I}_{0}$ is on-axis irradiation at $\mathrm{Z}=0$ and $\mathrm{L}_{\text {eff }}$ is effective thickness of the sample.

The effective thickness of the specimen was calculated using following expression:

$$
L_{e f f}=\frac{1-e^{(-\alpha L)}}{\alpha}
$$

Nonlinear absorption coefficient $(\beta)$ of $2 \mathrm{~A} 5 \mathrm{CP} 4 \mathrm{AB}$ from open aperture Z-scan method was determined as follows:

$$
\beta=\frac{2 \sqrt{2} \Delta T}{I_{0} L_{e f f}} \mathrm{~cm} / \mathrm{W}
$$

The real part and imaginary parts of third order nonlinear susceptibility values of $2 \mathrm{~A} 5 \mathrm{CP} 4 \mathrm{AB}$ were evaluated using the following relations:

$$
\operatorname{Re} \chi^{(3)}(e s u)=10^{-4} \frac{\left(\varepsilon_{o} C^{2} n_{o}^{2} n^{2}\right)}{\pi}\left(\frac{\mathrm{cm}}{\mathrm{W}}\right)
$$



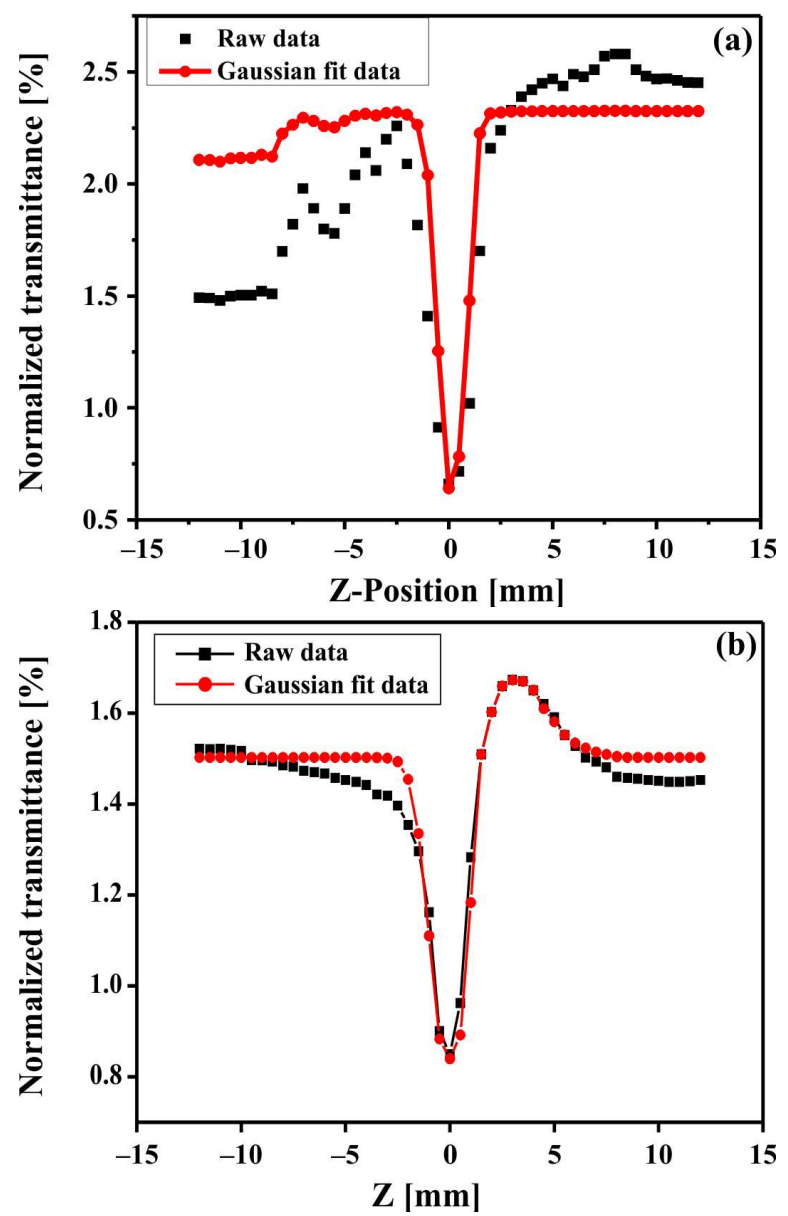

Fig. 7. (a) normalized transmittance with open aperture as a function of distance, (b) normalized transmittance with closed aperture as a function of distance.

$$
\operatorname{Im} \chi^{(3)}(e s u)=10^{-2} \frac{\left(\varepsilon_{o} C^{2} n_{o}^{2} \lambda \beta\right)}{4 \pi^{2}}\left(\frac{\mathrm{cm}}{\mathrm{W}}\right)
$$

Herein, $\epsilon_{\mathrm{o}}$ represents the vacuum permittivity, $\mathrm{C}$ is the velocity of light in vacuum.

The absolute value of $\chi^{(3)}$ of $2 \mathrm{~A} 5 \mathrm{CP} 4 \mathrm{AB}$ compound was calculated from the following relation:

$$
-\chi^{(3)}-=\left[\left(\operatorname{Re} \chi^{(3)}\right)^{2}+\left(\operatorname{Im} \chi^{(3)}\right)^{2}\right]^{\frac{1}{2}}
$$

The calculated values of nonlinear refractive index $\left(\mathrm{n}_{2}\right)$, nonlinear absorption coefficient and third order susceptibility of $2 \mathrm{~A} 5 \mathrm{CP} 4 \mathrm{AB}$ single crystal: $1.68913 \times 10^{-6} \mathrm{~cm}^{2} / \mathrm{W}, 1.92323 \times 10^{-5} \mathrm{~cm} / \mathrm{W}$ and $2.1193 \times 10^{-7}$ esu, respectively, indicate that the title compound crystal has a positive value of refractive index. It is clear that positive value of refractive index suggests self-focussing nature and two photon absorption process of $2 \mathrm{~A} 5 \mathrm{CP} 4 \mathrm{AB}$, when the crystal sample is exposed to continuous laser radiation (Table 1). This phenomenon is considered as one of the essential factors implying that the title compound can be employed for optical limiting applications [28, 29]. It was also observed that when laser light was passed through the crystalline sample, a part of energy was absorbed and converted into heat. Consequently, local increase in temperature could increase energy inside the specimen. As a result of the passage of continuous laser beam, variation in spatial distribution of refractive index could be observed in the specimen. Thermal effects due to the continuous wave laser beam are the predominant optical mechanism [31-33].

The variation in refractive index spatial distribution in the specimen was estimated using the following relation [31]:

$$
\Delta n=n-n=\frac{\sqrt{ } 2 \lambda}{2 \pi L \alpha} \frac{\Delta T p-v}{0.406(1-S)^{0.25}}
$$

where $\alpha$ is linear absorption coefficient of the sample along length $\mathrm{L}$.

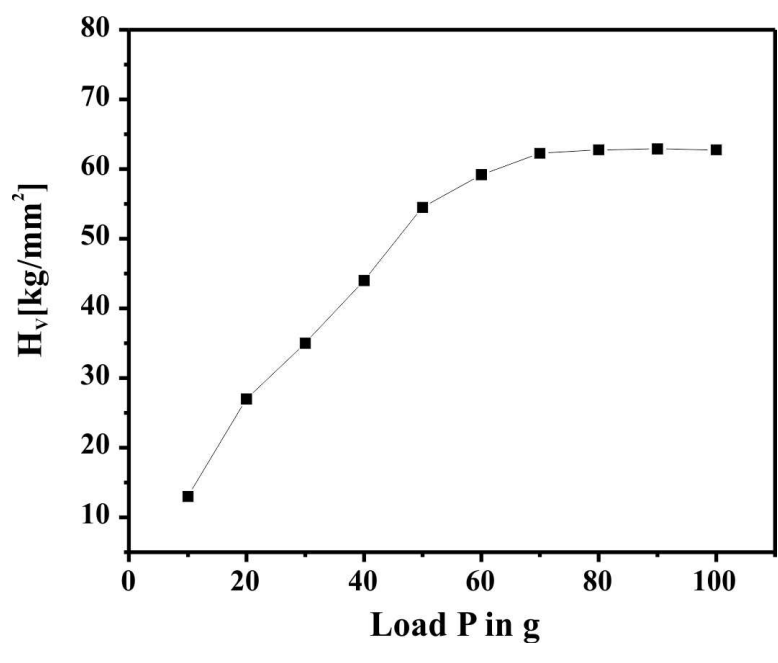

Fig. 8. Plot of microhardness versus load.

\subsection{Vickers microhardness studies}

The microhardness of the grown $2 \mathrm{~A} 5 \mathrm{CP} 4 \mathrm{AB}$ crystal was calculated using a Vickers 
Table 1. Evaluated third order nonlinear properties of 2A5CP4AB crystal.

\begin{tabular}{ll}
\hline Laser beam wavelength & $(\lambda)=632.8 \mathrm{~nm}$ \\
Laser power & $(\mathrm{P})=35 \mathrm{~mW}$ \\
Lens focal length & $(\mathrm{f})=24 \mathrm{~cm}$ \\
Optical path difference & $(\mathrm{Z})=175 \mathrm{~cm}$ \\
Effective thickness & $\left(\mathrm{L}_{\text {eff }}\right)=2.5 \mathrm{~mm}$ \\
Aperture radius & $\left(\mathrm{r}_{\mathrm{a}}\right)=4 \mathrm{~mm}$ \\
Spot diameter at focal length & $(\mathrm{Wa})=7.7 \times 10^{-6} \mathrm{~m}$ \\
Incident intensity at the focus & $(\mathrm{Z}=0)=2 \mathrm{~mW} / \mathrm{cm}^{2}$ \\
Nonlinear refractive index & $\left(\mathrm{n}_{2}\right)=1.6891 \times 10^{-6} \mathrm{~cm}^{2} / \mathrm{W}$ \\
Nonlinear absorption coefficient & $(\beta)=1.92 \times 10^{-5} \mathrm{~cm}_{\mathrm{W}}$ \\
Third order NLO susceptibility & $(\chi(3))=2.11 \times 10^{-7} \mathrm{esu}$ \\
Variation in refractive index spatial distribution at $\lambda=632.8 \mathrm{~nm}$ & $(\Delta \mathrm{n})=0.131586$ \\
\hline
\end{tabular}

microhardness tester (HMV-2) with a diamond pyramidal indenter having face angle of $136^{\circ}$ and resolution of $0.01 \mu \mathrm{m}$, employed with light microscope. The indentations were made on the surface of the sample with loads varying from $10 \mathrm{~g}$ to $100 \mathrm{~g}$ at a constant indentation time of $10 \mathrm{~s}$. It was observed that, for the load exceeding $100 \mathrm{~g}$, microcracks were developed on the surface of the sample. Consequently, the maximum load was restricted to $100 \mathrm{~g}$ and Vickers microhardness number $\mathrm{H}_{\mathrm{V}}$ of $2 \mathrm{~A} 5 \mathrm{CP} 4 \mathrm{AB}$ crystal was calculated using the relation:

$$
H_{V}=\frac{1.8544 P}{d^{2}} \mathrm{~kg} / \mathrm{mm}^{2}
$$

where $\mathrm{P}$ is the load applied and $\mathrm{d}$ is the average diagonal length of indentations formed, in millimeter. The Vickers microhardness value was calculated for the $2 \mathrm{~A} 5 \mathrm{CP} 4 \mathrm{AB}$ crystal. Vickers microhardness number as a function of the applied load is shown in Fig. 8. It is clear from the graph that the microhardness value of the title compound increases with increasing load.

\section{Conclusions}

A third order nonlinear optical material, 2-amino 5-chloropyridinium-4-amino benzoate was synthesized. Single crystals of $2 \mathrm{~A} 5 \mathrm{CP} 4 \mathrm{AB}$ were grown by solution growth method at room temperature. The single crystal X-ray diffraction analysis confirmed centrosymmetric space group of the title compound and powder X-ray diffraction analysis established the crystallinity of the grown crystals. The metastable zone width and solubility of $2 \mathrm{~A} 5 \mathrm{CP} 4 \mathrm{AB}$ compound were studied. UV-Vis absorption analysis showed the transition at a wavelength of $353 \mathrm{~nm}$, which confirmed formation of charge transfer compound. The absorption spectrum corresponding to $2 \mathrm{~A} 5 \mathrm{CP} 4 \mathrm{AB}$ showed the occurrence of hypsochromic shift at the wavelength due to strong electron donating ability of 2A5CP to PABA. Transparency of the grown single crystals of $2 \mathrm{~A} 5 \mathrm{CP} 4 \mathrm{AB}$ was studied with the aid of UV-Vis transmission spectroscopy. The 2A5CP4AB crystal showed transparency beyond $353 \mathrm{~m}$ region, which is a desired property for NLO applications. The optical band gap of $2 \mathrm{~A} 5 \mathrm{CP} 4 \mathrm{AB}$ crystal was estimated from transmittance values. The photoluminescence study showed the usefulness of the material in nonlinear optical applications. Vickers microhardness test revealed that microhardness of the material increases with increasing load. Z-scan study of the title compound crystal showed that the material could be employed in optical limiting applications. Hence, the 2A5CP4AB single crystal could be a good candidate for third order nonlinear optical (NLO) applications.

\section{Acknowledgements}

The authors are grateful to Dr. D. Sastikumar, National Institute of Technology (NIT), Tiruchirappalli, for extending help with Z-Scan measurements. 


\section{References}

[1] Periyasamy B.K., Jebas R.S., Thailampillai B., Mater. Lett., 61 (2007), 1489.

[2] Prasad P.N., Williams D.J., Introduction to Nonlinear Optical Effects in molecules and Polymers, Wiley, New York, 1991.

[3] Carolin M.L., Vasudevan S., Mater. Lett., 62 (2008), 2245.

[4] Anandha Babu G., Sreedhar S., Venugopal R., RAMASAMY P., J. Cryst. Growth, 312 (2010), 1957.

[5] Santhakumari S., Ramamurthi K., Spectrochim. Acta A, 78 (2011), 653.

[6] Dhanraj P.V., Rajesh N.P., Vinitha G., BhagaVAnnarayana G., Mater. Res. Bull., 46 (2011), 726.

[7] BrahadeEswaran S., Onduka S., TAKagi M., TAKahashi Y., ADACHI H., Yoshimura M., MORI Y., SASAKI T., J. Cryst. Growth, 292 (2006), 441.

[8] Brahadeeswaran S., Onduka S., Takagi M., TAKAHASHI Y., ADACHI H., KAMIMURA T., Yoshimura M., Mori Y., Yoshida K., SASAKI T., Cryst. Growth Des., 6 (2006), 2643.

[9] Robinson F.A., The vitamin Co-factors of Enzyme Systems, Pergamon, London, 1966.

[10] Pauling L., HAYWARD R., The Architecture of Molecules, W.H. Freeman, San Francisco, 1964.

[11] Gracin S., Rasmuson A.C., Cryst. Growth Des., 4 (2004), 1013.

[12] Etter M.C., Frankenbach G.A., Chem. Mater., 1 (1989), 10.

[13] Kashino S., Sumida Y., Haisa M., Acta Crystallogr. $B, 28$ (1972), 1374.

[14] Kashino S., Acta Crystallogr. B, 29 (1973), 1836.

[15] Rademeyer M., OverbeeK G.E., Liles D.C., Acta Crystallogr. E, 66 (2010), 1634.

[16] Brahadeeswaran S., Venkataraman V., Bhat H.L., J. Cryst. Growth, 205 (1999), 544.

[17] Wu J.I., Gopalakrishnan R., Tai C. ID., LaW C.W., Jpn. J. Appl. Phys., 43 (2004), 1507.

[18] Shanmugam G., Brahadeeswaran S., Spectrochim. Acta A, 95 (2012), 177.
[19] Kwon S.J., JazbinseK M., Kwon O.P., Gunter P., Cryst. Growth Des., 10 (2010), 1552.

[20] MERCURY 1.3., Cambridge Crystallographic Data centre, CCDC Software Limited, Cambridge, UK, 2004.

[21] Kannan V., Sugumar P., Brahadeeswaran S., Ponnuswamy M.N., Acta Crystallogr. E, 8 (2012), 3187.

[22] Fasone S., Grasso D., Gandolfo C., J. Mol. Struct., 20 (1974), 449.

[23] Sharma Y.R., Elementary organic spectroscopy, S. Chand, New Delhi, 1996.

[24] Shanmugam G., Belsley M.S., Isakov D., Matos Komas E.D., Nehru K., BRAHadeeswaran S., Spectrochim. Acta A, 95 (2012), 177.

[25] TAUC J.C., The optical properties of solids, Academic Press, North-Holland, 1972.

[26] Aravindan A., Srinivasan P., Cryst. Res. Technol., 11 (2007), 1097.

[27] Sabarigirisun T.C., Dhanuskodi S., Cryst. Res. Technol., 44 (2009), 1297.

[28] Wolfersberger D., Fressengeas N., MaUfOY J., Kugel G., J. Nonlinear. Opt. Phys., 9 (2000), 441.

[29] Thirupugalmani K., Karthick S., Shanmugam G., Kannan V., SRidhar B., Nehru K., BrahadeESWARAN S., Opt. Mater., 49 (2015), 158.

[30] Arun K.J., JeyalaKshmi S., Optoelectron. Adv. Mat., 2 (2008), 701.

[31] Boyd R.W., Nonlinear Optics, Elsevier, USA, 2008.

[32] Cheung Y.M., GaYen S.K., J. Opt. Soc. Am. B, 11 (1994) 636.

[33] Rodriguez L., Ahn H.Y., Belfield D.K., Opt. Express, 17 (2009), 19617.

Received 2016-06-18 Accepted 2017-05-15 